\title{
Formulation and In vitro Release Behavior of Hydroxypropyl Methylcellulose (HPMC) Matrix Tablet Containing Poorly Soluble Fenofibrate
}

\author{
Ramesh Kandel, Tushar Saha, Zia Uddin Masum and Jakir Ahmed Chowdhury \\ Department of Pharmaceutical Technology, Faculty of Pharmacy, University of Dhaka, Dhaka-1000 \\ Bangladesh
}

(Received: December 11, 2020; Accepted: January 28, 2020; Published: January 30, 2020)

\begin{abstract}
Fenofibrate, a water insoluble drug was used to prepare matrix tablet with four different viscosity grades of Hydroxypropyl Methylcellulose (HPMC) which were Methocel K4M CR, Methocel K15M CR, Methocel K100M CR and Methocel K100LV CR. The concentration of those excipients was 5, 10, 20, and $40 \%(\mathrm{w} / \mathrm{w})$, respectively. The content of drug in a fixed quantity of powder in every formulation was ranged between 96.47 to $104.78 \%$. The dissolution study was done by using USP dissolution apparatus II. The kinetics of release was analyzed by using zero-order, first order, Korsmeyer-Peppas, Higuchi and Hixon-crowell equations to explain the drug release mechanism from the matrix tablets. In-vitro dissolution profile of matrix tablets were dependent upon the HPMC concentration and dissolution was rapid for tablets containing lower polymer proportion i.e. 5,10, and 20\% Percentage (w/w) HPMC than those containing $40 \%$ (w/w) HPMC.
\end{abstract}

Key words: Fenofibrate, HPMC, matrix tablet, release kinetics.

\section{Introduction}

The reliability of therapy and compliance can be easily augmented by administrating the sustained release formulation (Lordi, 1986). Sustained release formulation is a precursor which can achieve the steady-state drug concentration in systemic circulation for an extended time period in a way which is therapeutically safe and non toxic. Again, sustained release dosage form can be easily reduced and fully overcome limitations of conventional therapy. As, sustained release dosage forms maintain the steady drug plasma concentration level for a prolong periods of time this why the variations of drug levels in the blood are prevented which actually prevent the drug related side effects (Chein, 1992). Fenofibrate, a hypolipidemic drug is extensively used to reduce the concentration of triglyceride and cholesterol in plasma. Low-density lipoprotein (LDL) and very low-density lipoprotein (VLDL) level are decreased by fenofibrate. It also increases the level of high-density lipoprotein (HDL) which makes this drug superior in lipid regulation. Fenofibrate has low solubility and high permeability and this why it is in the Class II drugs of Biopharmaceutics Classification System (BCS) (Granero et al., 2005). The bioavailability of Fenofibrate depends on the environment of gastrointestinal tract this why modification in the dissolution medium is necessary to increase its solubility. Addition of surfactant in a controlled way may be a wise approach to control over GI fluid condition so that the solubility of Fenofibrate can be improved as it has no ionizable group so the solubility of Fenofibrate will not be influenced by changing the $\mathrm{pH}$ of the medium

Correspondence to: Jakir Ahmed Chowdhury; Email: jakir@du.ac.bd

DOI: https://doi.org/10.3329/bpj.v23i1.45314 
(Jamzad and Fassihi, 2006). The objective of this research is to find out the way of enhancing the solubility of Fenofibrate (matrix tablet) by using different grades of HPMC.

\section{Materials and Methods}

Fenofibrate was obtained from Beximco Pharmaceuticals Limited (BPL), Bangladesh. Methocel K4M CR, Methocel K15M CR, Methocel K100M CR and Methocel K100LV CR were obtained from Dow chemical company, USA. Starch 1500 was obtained from Colorcon, Bangladesh Ltd. Other excipients Colloidal Silicon dioxide were obtained from Cabot India Ltd, Mumbai and Magnesium Stearate were obtained from Dr. Paul Lohmann GmbH KG, Germany. Sodium lauryl sulfate was purchased from Mitford, Dhaka.

Preparation of dissolution medium: For 1 liter 0.1 M Sodium lauryl sulfate solution, $28.83 \mathrm{gm}$ Sodium lauryl sulfate was dissolved in 1 liter distilled water.

Preparation of matrix tablet: The tablet was formulated by normal mixing of active pharmaceutical ingredient (API) with the polymers, filler, binder and lubricant using direct compression method. Using a pestle and mortar drug, HPMC and remaining excipients (except the lubricant) were mixed thoroughly. Magnesium stearate (Lubricant), was added and mixed further. The mixture of granules was compressed into $300 \mathrm{mg}$ tablet of 13 $\mathrm{mm}$ diameter using hydraulic press (Perkin Emler, UK). The drug content of fenofibrate was kept constant at $100 \mathrm{mg}$ in each matrix tablet but the HPMC concentration was varied. HPMC powder was used into four different size fractions at concentration levels from 5 to 40 percentage.

Assay of Fenofibrate in matrix tablet: Methanol using as the extracting solvent for determined the drug content and the assay samples were analyzed spectrophotometrically (Shimadzu UV-1650PC, Japan) at $291 \mathrm{~nm}$ (Dhabale and Gharge, 2010) Accurately $16 \mathrm{mg}$ of Fenofibrate was weighed into $100 \mathrm{ml}$ volumetric flask which was clean and dry, $50 \mathrm{ml}$ of methanol was added, shake for 10 minutes and made volume with methanol. Five Fenofibrate tablets (100 mg Fenofibrate) were dispensed and powdered. A portion equivalent to $16 \mathrm{mg}$ of Fenofibrate was weighed into $100 \mathrm{ml}$ volumetric flask which was clean and dry. Then added about 70 $\mathrm{ml}$ of methanol on that and shook for 10 minutes and volume made up to the mark with extracting solvent (methanol). Mixed well and filtered through Whatman filter paper No. 41. First few ml filtrates discarded and then $10 \mathrm{ml}$ of filtrate was taken out from pipette and diluted to $100 \mathrm{ml}$ with mobile phase. Then all the absorbencies were recorded at the respective wavelengths.

Differential Scanning Calorimetry (DSC): Thermograms of the drug, excipients and final formulation were recorded using a DSC-60 calorimeter (Shimadzu, Crop. Japan). Approx. 05 mg samples were dispensed into a DSC pans (aluminum), crimped at $27{ }^{0} \mathrm{c}$ and increase temperature up to $100^{\circ} \mathrm{C}$ at $1.0^{\circ} \mathrm{C} / \mathrm{min}$ rate with the help of nitrogen gas purge at $100 \mathrm{ml} / \mathrm{min}$. In formulation at $80{ }^{\circ} \mathrm{c}$ was observed characteristic endothermic peak of the drug. However, impurities from excipients are more responsible decreases the intensity of the drug peak in optimized formulation than physical interaction of the drug with the components.

Drug release studies: The Fenofibrate release from HPMC matrix tablets were determined by the USP II paddle method at $75 \mathrm{rpm}$ rotation speed in $1000 \mathrm{ml}$ of dissolution medium at $37+0.5^{\circ} \mathrm{c}$ with the help of dissolution tester (ERWEKA DT 600, Germany) (Jamzad and Fassihi, 2006). The dissolution media used was 0.1 molar sodium lauryl sulfate (SLS) solution. $10 \mathrm{ml}$ dissolution sample were collected after a given interval and refilled the sampling volume with fresh test medium. Then collected samples were filtered through 0.44 um filter paper. The concentration of Fenofibrate in the dissolution samples was spectrophotometrically determined at $291 \mathrm{~nm}$ using Spectrophotometer (Shimadzu UV-1650PC, Japan). Each batch of tablets, dissolution tests were performed up to 8 hours in triplicate and averaged the results. 


\section{Results and Discussion}

For this research, Cellulose derivatives of four different grades such as Methocel K15M CR, Methocel K4M CR, Methocel K100M CR, and Methocel K100 LV CR were used for the development of Fenofibrate sustained release matrix tablet using direct compression method. The effect of Methocel K15M CR, Methocel K4M CR, Methocel K100M CR, and Methocel K100 LVCR on the release of Fenofibrate from the matrix tablet was assessed. According to design of study, HPMCMethocel different percentage $(5 \%, 10 \%, 20 \%$ and $40 \%$ ) containing matrix tablets were kept in the dissolution media. The percent release of fenofibrate from all the tablets were plotted against time to study the release pattern of drug. It was observed in the formulations that drug release percentage was increased by reducing the amount of Methocel (Table 1). The content of drug in a weighed amount of powder for all formulations ranged from 96.47 to $104.78 \%$.

The Methocel K15M CR polymer was used individually with Fenofibrate as the matrix former in the formulations MK15M5, MK15M10, MK15M20, and MK15M40 as 5\%, 10\%, 20\% and 40\% of the full weight of the tablet respectively. This ranges of Methocel K15 M CR were chosen considering physical and chemical characteristics of the polymer and drug in the physiological environment.

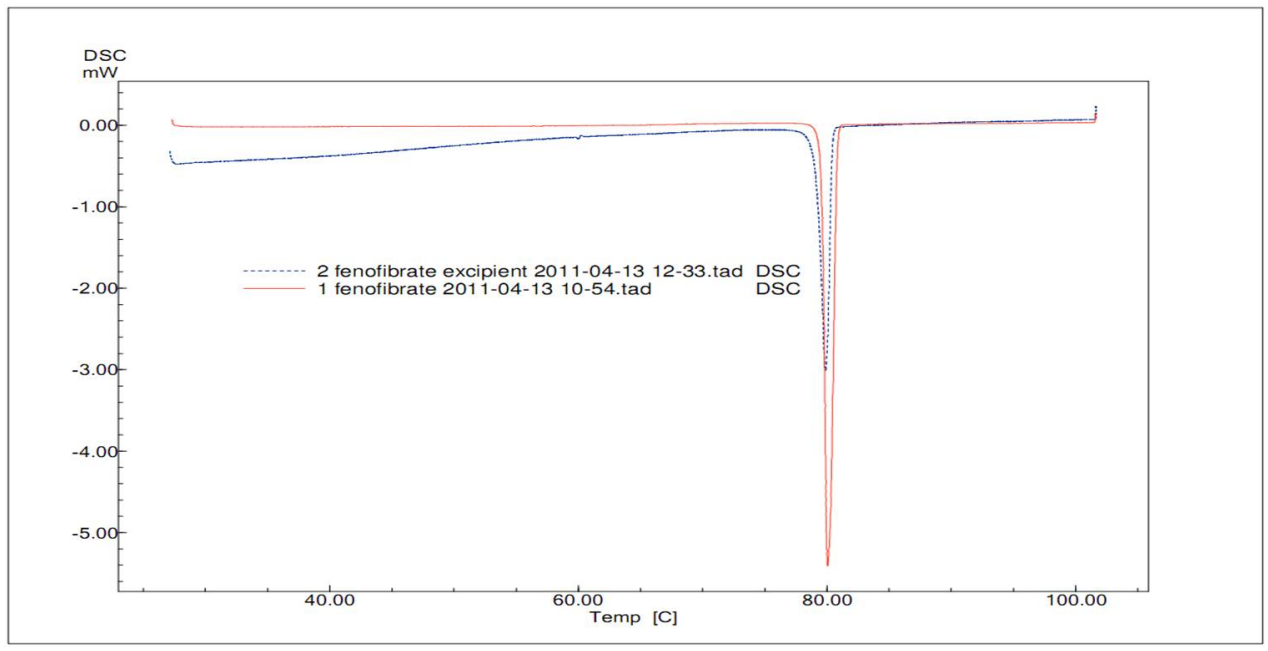

Figure 1. DSC thermograms of (1) Fenofibrate and (2) Fenofibrate with excipients.

Formulation M 0, MK15M5, MK15M10, MK15M20 and MK15M40 released 99.35\%, 97.11 $\%, 99.17 \%, 98.24 \%$, and $77.62 \%$ drug respectively after 8 hours. Highest amount of drug was released from formulation containing $0 \%$ polymer, whereas formulation containing $40 \%$ polymer released 77.61 $\%$ Fenofibrate after 8 hours. The level of Methocel $\mathrm{K} 15 \mathrm{M}$ CR present in the matrix structure was found to be inversely related to the rate and extent of drug release, i.e., Decrease in the polymeric content of the matrix which increase the drug release. Increase in the content of polymer which results in a decrease in the drug release due to decrease in the total porosity of matrix. Depending on the polymer proportion, the initial release for the first hour varied between 9 to 41 $\%$ for Methocel K15M CR, but the drug release was found to be more controlled in the later stages in the tablets with a higher proportion of the polymer.

In another experiment, the polymer Methocel K4M CR was used individually with Fenofibrate as the matrix former in the proposed formulations MK4M5, MK4M10, MK4M20, and MK4M40 as 5 $\%, 10 \%, 20 \%$, and $40 \%$ of the weight of the tablet respectively. Formulation MK4M5, MK4M10, MK4M20 and MK4M40 released $98.72 \%, 96.12 \%$, 
$86.89 \%$, and $74.18 \%$ drug respectively after 8 hours. Formulations containing $0 \%$ polymer released 99.35\% drug after 3 hours, whereas formulation containing highest amount of polymer i.e. $40 \%$ released $74.18 \%$ Fenofibrate after 8 hours.
Depending on the polymer proportion, the initial release for the first hour varied between 8 to $35 \%$ for Methocel K4M CR, but the drug release was found to be more controlled in the later stages in the tablets with a higher proportion of the polymer.

Table 1. Composition of Fenofibrate (FNO) matrix tablets (mg/tablet).

\begin{tabular}{llllllllll}
\hline $\begin{array}{l}\text { Formulation } \\
\text { Code }\end{array}$ & $\begin{array}{l}\text { FNO } \\
(\mathrm{mg})\end{array}$ & $\begin{array}{l}\text { Methocel } \\
\text { K15M CR } \\
(\mathrm{mg})\end{array}$ & $\begin{array}{l}\text { Methocel } \\
\text { K4M CR } \\
(\mathrm{mg})\end{array}$ & $\begin{array}{l}\text { Methocel } \\
\text { K100M CR } \\
(\mathrm{mg})\end{array}$ & $\begin{array}{l}\text { Methocel } \\
\text { K100LV } \\
\text { CR }(\mathrm{mg})\end{array}$ & $\begin{array}{l}\text { Starch } \\
1500 \\
(\mathrm{mg})\end{array}$ & $\begin{array}{l}\text { Mg- } \\
\text { stearate } \\
(\mathrm{mg})\end{array}$ & $\begin{array}{l}\text { Aerosil } \\
(\mathrm{mg})\end{array}$ & $\begin{array}{l}\text { Total } \\
\text { Wt. } \\
(\mathrm{mg})\end{array}$ \\
\hline M0 & 100 & 0 & - & - & - & 196 & 2 & 2 & 300 \\
MK15M5 & 100 & 15 & - & - & - & 181 & 2 & 2 & 300 \\
MK15M10MK1 & 100 & 30 & - & - & - & 166 & 2 & 2 & 300 \\
5M20 & 100 & 60 & - & - & - & 136 & 2 & 2 & 300 \\
MK15M40 & 100 & 120 & - & - & - & 76 & 2 & 2 & 300 \\
MK4M5 & 100 & - & 15 & - & - & 181 & 2 & 2 & 300 \\
MK4M10 & 100 & - & 30 & - & - & 166 & 2 & 2 & 300 \\
MK4M20 & 100 & - & 60 & - & - & 136 & 2 & 2 & 300 \\
MK4M40 & 100 & - & 120 & - & - & 76 & 2 & 2 & 300 \\
MK100M5 & 100 & - & - & 15 & - & 181 & 2 & 2 & 300 \\
MK100M10 & 100 & - & - & 30 & - & 166 & 2 & 2 & 300 \\
MK100M20 & 100 & - & - & 60 & - & 136 & 2 & 2 & 300 \\
MK100M40 & 100 & - & - & 120 & - & 76 & 2 & 2 & 300 \\
MK100LV5 & 100 & - & - & - & 15 & 181 & 2 & 2 & 300 \\
MK100LV10 & 100 & - & - & - & 30 & 166 & 2 & 2 & 300 \\
MK100LV20 & 100 & - & - & - & 60 & 136 & 2 & 2 & 300 \\
MK100LV40 & 100 & - & - & - & 120 & 76 & 2 & 2 & 300 \\
\hline
\end{tabular}

In other experiment, the polymer Methocel K100M CR was used individually with Fenofibrate as the matrix former in the proposed formulations MK100M5, MK100M10, MK100M20, and MK100M40 as 5\%,10\%, 20\% and $40 \%$ of weight of the tablet respectively. Formulation MK100M5, MK100M10, MK100M20 and MK100M40 was $99.29 \%, 96.70 \%, 74.44 \%$ and $66.95 \%$, respectively. Formulations containing 5\% polymer released 99.29\% drug in 8 hours, whereas formulations containing $40 \%$ polymer released $66.95 \%$ Fenofibrate after 8 hours. Depending on the polymer proportion, the initial release for the first hour varied between 8 to $66 \%$ for Methocel K100M CR, but the drug release was found to be more controlled in the later stages in the tablets with a higher proportion of the polymer. Another experiment was designed to access the effect of concentration of Methocel
K100LV CR on release of Fenofibrate from matrix tablet. The polymer Methocel K100M CR was used with Fenofibrate as the matrix former in the proposed formulations MK100LV5, MK100LV10, MK100LV20, and MK100LV40 as 5\%, 10\%, 20\%, and $40 \%$ of the total weight of the tablet respectively. Formulation MK100LV5, MK100LV10, MK100LV20 and MK100LV40 released 98.15\%, $100.31 \%, 93.59 \%$, and $66.95 \%$, respectively after 8 hours. Formulation containing $5 \%$ polymer released 98.15\% drug after 8 hours, whereas formulations containing $40 \%$ polymer released $92.66 \%$ Fenofibrate after 8 hours. Depending on the polymer proportion, the initial release for the first hour varied between 13 to $74 \%$ for Methocel K100LV CR, but the drug release was found to be more controlled in the later stages in the tablets with a higher proportion of the polymer. 


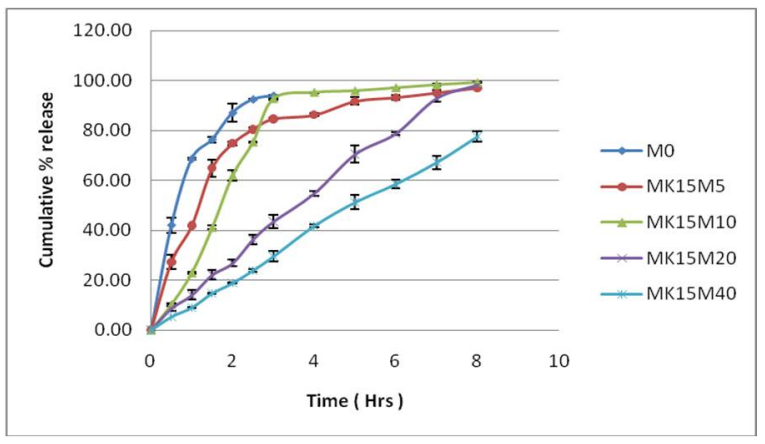

Figure 2. Zero order plot of release kinetics of fenofibrate from methocel K15 M matrices.

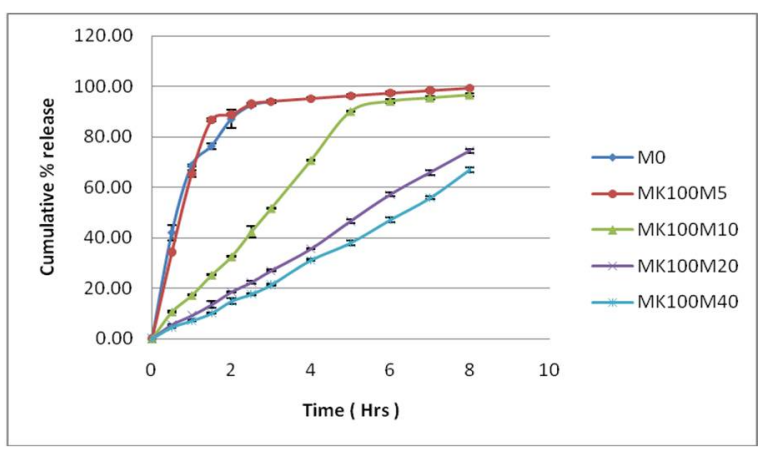

Figure 4. Zero order plot of release kinetics of fenofibrate from methocel K100 M matrices.

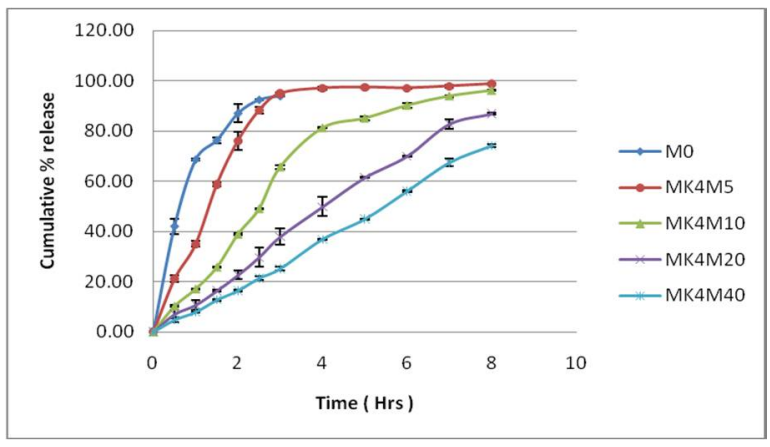

Figure 3. Zero order plot of release kinetics of fenofibrate from methocel $\mathrm{K} 4 \mathrm{M}$ matrices.

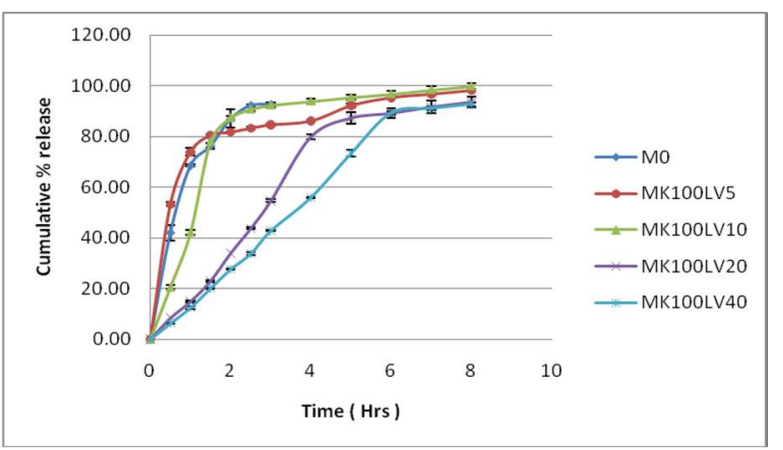

Figure 5. Zero order plot of release kinetics of fenofibrate from methocel K100 LV matrices..

Table 2. Kinetic parameters of Fenofibrate matrix tablets.

\begin{tabular}{|c|c|c|c|c|c|c|c|c|c|c|c|}
\hline \multirow{2}{*}{$\begin{array}{l}\text { Formulation } \\
\text { Code }\end{array}$} & \multicolumn{2}{|c|}{ Zero order } & \multicolumn{2}{|c|}{ First order } & \multicolumn{2}{|c|}{ Higuchi } & \multicolumn{2}{|c|}{ krosmeyer } & \multicolumn{2}{|c|}{ Hixon-crowell } & \multirow{2}{*}{$\begin{array}{l}\text { MDT } \\
\text { (hrs) }\end{array}$} \\
\hline & $\mathrm{R}^{2}$ & $\mathrm{~K}_{0}$ & $\mathrm{R}^{2}$ & $\mathrm{~K}_{1}$ & $\mathrm{R}^{2}$ & $\mathrm{k}_{\mathrm{H}}$ & $\mathrm{R}^{2}$ & $\mathrm{n}$ & $\mathrm{R}^{2}$ & $\mathrm{k}_{\mathrm{HC}}$ & \\
\hline M0 & 0.528 & 8.298 & 0.966 & 0.262 & 0.791 & 31.779 & 0.855 & 2.026 & 0.840 & 3.638 & 0.9 \\
\hline MK15M5 & 0.678 & 9.684 & 0.965 & 0.181 & 0.888 & 34.684 & 0.813 & 1.294 & 0.887 & 4.026 & 1.7 \\
\hline MK15M10 & 0.741 & 12.326 & 0.954 & 0.272 & 0.879 & 41.991 & 0.794 & 0.75 & 0.890 & 4.367 & 2.2 \\
\hline MK15M20 & 0.994 & 12.648 & 0.857 & 0.187 & 0.939 & 38.486 & 0.996 & 0.182 & 0.954 & 4.896 & 3.7 \\
\hline MK15M40 & 0.998 & 9.767 & 0.967 & 0.077 & 0.923 & 29.388 & 0.998 & 0.025 & 0.988 & 4.730 & 5.0 \\
\hline MK4M5 & 0.649 & 10.702 & 0.885 & 0.245 & 0.849 & 38.272 & 0.728 & 1.175 & 0.810 & 4.003 & 1.6 \\
\hline MK4M10 & 0.902 & 12.763 & 0.988 & 0.185 & 0.942 & 40.824 & 0.933 & 0.375 & 0.979 & 4.666 & 3.0 \\
\hline MK4M20 & 0.993 & 11.429 & 0.962 & 0.110 & 0.929 & 34.601 & 0.994 & 0.05 & 0.986 & 4.777 & 4.2 \\
\hline MK4M40 & 0.996 & 9.507 & 0.961 & 0.072 & 0.901 & 28.269 & 0.999 & 0.0093 & 0.980 & 4.750 & 4.4 \\
\hline MK100M5 & 0.491 & 8.305 & 0.909 & 0.232 & 0.751 & 32.131 & 0.703 & 2.128 & 0.761 & 3.544 & 0.8 \\
\hline MK100M10 & 0.941 & 13.297 & 0.958 & 0.208 & 0.938 & 41.545 & 0.973 & 0.305 & 0.967 & 4.799 & 3.2 \\
\hline MK100M20 & 0.999 & 9.367 & 0.965 & 0.071 & 0.912 & 27.992 & 0.999 & 0.045 & 0.983 & 4.731 & 5.4 \\
\hline MK100M40 & 0.996 & 8.2 & 0.957 & 0.056 & 0.891 & 24.274 & 0.998 & 0.155 & 0.975 & 4.724 & 6.2 \\
\hline MK100LV5 & 0.511 & 7.388 & 0.938 & 0.178 & 0.770 & 28.370 & 0.619 & 2.047 & 0.831 & 3.627 & 1.1 \\
\hline MK100LV10 & 0.573 & 9.816 & 0.908 & 0.289 & 0.796 & 36.202 & 0.619 & 1.509 & 0.839 & 3.892 & 1.3 \\
\hline MK100LV20 & 0.912 & 12.920 & 0.969 & 0.168 & 0.929 & 40.815 & 0.946 & 0.275 & 0.959 & 4.670 & 3.2 \\
\hline MK100LV40 & 0.975 & 12.858 & 0.949 & 0.156 & 0.928 & 39.258 & 0.988 & 0.137 & 0.972 & 4.835 & 3.7 \\
\hline
\end{tabular}


All the release data obtained from the different formulations were treated in distinct kinetics models such as Zero Order (Harland et al., 1998), First Order, Higuchi (Higuchi, 1963), Krosmeyer- peppas (Korsmeyer and Peppas, 1983), and Hixon-crowell model (Hixon and Crowell, 1931). To identify their release mechanism, the correlation coefficients were determined graphically. It is better to use as minimum amount of polymers and diluents in an ideal matrix tablets as possible, and releasing its drug over a reasonable time, and preferably follow zero order release pattern (Pather et al., 1998).

From table 2 it was found that, proposed formulations M0, MK15M5, MK15M10, MK4M5, MK100M5, and MK100LV10 followed first order kinetics. Formulations MK15M20, MK15M40, MK4M20, MK4M40, MK100M20, MK100M40, MK100LV20, and MK100LV40 followed zero order kinetics, whereas formulation MK4M10 followed both Krosmeyer and Hixon-crowell kinetics and formulation MK100LV5 followed First order and krosmeyer kinetics.

Release mechanism from matrices: The mechanism of drug release from Methocel K4M CR, Methocel K15M CR, Methocel K100M CR, and Methocel K100 LV CR is as like; swelling, hydration and diffusion of the drug particles. All Methocel viscosity grades used are hydrophilic polymers. Hydrophilic polymers which first hydrate in contact with dissolution fluid and then swell. At last it allows gradual dissolution and diffusion of drug from the matrix (Arthur, 2000). A number of porous channels were formed within the polymeric structure, when these polymers get hydrated in contact with dissolution fluid. Fluid enters slowly through the channels which was porous and the drug dissolves on the basis of their partition coefficient. After that, drug solution is released from the matrix. The main precursor of the dissolution and diffusion of the drug molecule were rate and extent of polymer hydration, number of channel formation, amount of fluid enter into the porous channel, number of multilayer formations, partition coefficient of the drug (Lee et al., 1999). From the research, it is found that
Methocel when used in concentration of 20 and 40 $\%$, can retard drug release from matrix tablets. However, retardation action of high viscosity grades of Methocel was better than low viscous grade i.e. Methocel K4M CR and Methocel K100LV CR. Swellable polymer depends on molecular weight; the larger the molecule, the stronger the forces holding the chains together for the release rate of the water (Renoylds et al., 1998). The polymer matrix form was complicated than from ordinary crystalline materials in the dissolution process. It is often noticed that swollen and gel layers form next to the diffusion layer (Sungthongjeen et al., 1999). It was also noticed that the release of the drug was decreased when the polymer percentage increased and in case of $40 \%$ Methocel K100M CR polymer the release pattern was $66.95 \%$ at $8^{\text {th }}$ hour, whereas same concentration of Methocel K15M CR released 77.62\%, Methocel K4M CR released $74.18 \%$, and Methocel K100LV CR released $92.66 \%$ drug after 8 hours. The drug release retardation action was observed from higher viscosity grades. It is happened due to multilayer formation in the tablet matrix. The tablet matrix became swollen and channels were formed to penetrate dissolution fluid into the matrix when it was hydrated, which dissolves the drug and finally diffused. It was not straight forward pathway and release of drug was retarded because of formation of multilayer.

\section{Conclusions}

This study presents the evaluation for sustained release Fenofibrate matrix tablet prepared by direct compression. Based on the results obtained, it is possible to formulate promising sustained release oral matrix tablet containing HPMC in a specific range of concentration. As expected, percent fenofibrate release was found to be significantly reduced by an increase in polymer level from 5 to $40 \%$. Increase in starch level was found to increase fenofibrate release from HPMC matrices. Regulated drug release investigation shows that the hydrophilic matrix tablets of fenofibrate, HPMC used in preparation, can be employed successfully as a once- 
a-day oral sustained release matrix tablet. All the polymers used in this study could extent the drug release upto 8 hours so it helps to achieve the low plasma concentration to reduce side effects. To establish a successful formulation, it is essential to arrange extensive IVIVC studies on similar formulations from the biopharmaceutical viewpoint.

\section{References}

Lordi, N.G. 1986. In: The Theory and Practice of Industrial Pharmacy (Lachman, L., Lieberman, H.A. and Kiang, J.L., Eds.), Lea and Febiger, Philadelphia, PA, pp. 430-456.

Chein, Y.W. 1992. In: Novel Drug Delivery System. Marcel Dekker- Inc, New York, p. 139.

Granero, G.E., Ramachandran, C. and Amidon, G.L. 2005. Dissolution and solubility behavior of fenofibrate in sodium lauryl sulfate solutions. Drug Development and Industrial Pharmacy 31(9), 917-22.

Jamzad, S. and Fassihi, R. 2006. Role of surfactant and pH on dissolution properties of fenofibrate and glipizide a technical note. AAPS Pharm. Sci. Tech. 33.

Dhabale, P.N., and Gharge, D.S. 2010. Simultaneous spectrophotometric estimation of atorvastatin and fenofibrate in bulk drug and dosage form by using simultaneous equation method. Inte. J. Chem. Tech. Res. 2, 325-328.

Harland, R., Dubernet, C., Benoit, J.P. and Peppas, N. 1998. A model of dissolution-controlled, diffusional drug release from non-swellable polymeric microspheres. J. Controlled Rel. Res. 7, 207-215.
Higuchi, T. 1963. Mechanism of sustained action medication. Theoretical analysis of rate of release of solid grugs dispersed in solid matrices. J. Pharm. Sci. 52, 1145-1149.

Korsmeyer, R, W., Peppas, N.A. 1983. In: Controlled release delivery systems. (Roseman, T.J. and Mansford ,S.Z. Eds.), Marcel Dekker, New York, p. 77-90.

Hixon, A.W. and Crowell, J.H. 1931. Dependence of reaction velocity upon surface and agitation (I) theoretical consideration. Ind. Eng. Chem. 23,923-931.

Pather, S.I., Russel, I. Syce, J.A. and Neau, S.H. 1998. Sustained release theophylline by direct compression. Part I. Formulation and in-vitro testing. Int. J. Pharm. 164,1-10.

Arthur, H.K. 2000. Handbook of Pharmaceutical Excipients. American Pharmaceutical Association, Washington, D.C. pp. 252-255.

Lee, B.J., Ryu, S.G. and Cui, J.H. 1999. Formulation and release characteristics of hydroxypropyl methylcellulose matrix tablet containing melatonin. Drug Dev. Ind. Pharm. 25, 493-501.

Renoylds, D.T., Gehrke,S.H., Ajas, H.S. and Shenouda, L.S. 1998. Polymer erosion and drug-release characteristics of hydroxypropyl methylcellulose matrices. J. Pharm. Sci. 87, 1115-1123.

Sungthongjeen, S., Pitaksuteepong, T., Somsiri, A. and Sriamornsak, P. 1999. Studies on pectin as potential hydrogel matrices for controlled-release drug delivery. Drug Dev. Ind. Pharm. 25, 1271-76. 